\title{
Diarrea por citomegalovirus (CMV) como primera manifestación de sida
}

\author{
F.J. GARCÉS MOLINA, A. ROYO GARCÍA, G. HERNÁNDEZ PÉREZ, B. PINILLA, \\ L. PASTOR GÓMEZ-CORNEJO, J. PORTUGAL ÁLVAREZ
}

Servicio de Medicina Interna II. Hospital General Universitario Gregorio Marañón. Madrid

\author{
CYTOMEGALOVIRUS (CMV) DIARRHEA AS DIAGNOSTIC INDEX \\ FOR AIDS
}

\section{RESUMEN}

Se presenta el caso de un varón de 49 años, sin antecedentes personales de interés salvo agresión sexual en 1996, que acude al Servicio de Urgencia del HGUGM por cuadro de diarrea de 6 meses de evolución, al que se añade fiebre de hasta $39^{\circ} \mathrm{C}$ en los últimos 2 meses.

Durante su ingreso es diagnosticado de infección por el Virus de la Inmunodeficiencia Humana (VIH), antigenemia para Citomegalovirus (CMV) de 70 células, y en el estudio de diarrea se objetiva CMV en cultivo celular de la biopsia de colon, con colonoscopia normal.

La colitis es la forma más frecuente de afectación del tubo digestivo por CMV en pacientes con infección por el VIH. No obstante, es poco frecuente como primera manifestación de Síndrome de Inmunodeficiencia Adquirida (SIDA), como ocurre en el caso que presentamos.

PALABRAS CLAVE: SIDA. Citomegalovirus. Colitis.

\begin{abstract}
We report a case of a male 49 years old, without clinical history, excepting rape in 1996, that was admitted to the Emergency Room of HGUGM because of diarrhea 6 months duration, plus fever $\left(39^{\circ} \mathrm{C}\right)$ in the last 2 months.

He was diagnosed of infection by the Human Immunodeficiency Virus (HIV), with serum antigenemia (70cells), and colonic biopsy positives for Cytomegalovirus, and a normal colonoscopy.

Cytomegalovirus colitis is the major etiologic infectious agent in patients with AIDS-associated diarrhea, although it can be the diagnostic index for AIDS in a few cases.
\end{abstract}

KEY WORDS: AIDS. Cytomegalovirus. Colitis.

Garcés Molina F.J, Royo García A, Hernández Pérez G, Pinilla B, Pastor Gómez-Cornejo L, Portugal Álvarez J. Diarrea por citomegalovirus (CMV) como primera manifestación de sida. An Med Interna (Madrid) 2000; 17: 647-648

\section{INTRODUCCIÓN}

La infección por CMV es frecuente en pacientes infectados por el VIH, siendo más frecuente en estadios avanzados de la enfermedad (menos de 100 CD4) (1). La afectación digestiva es la segunda en frecuencia después de la retinitis, siendo la colitis la forma más frecuente de afectación del tubo digestivo (2).

En general, para asumir el diagnóstico definitivo de enfermedad por CMV en pacientes con infección por el VIH es necesario estudio histológico, aunque una clara sospecha clínica junto con exclusión de otros agentes etiológicos y la demostración de infección por CMV, justifican el tratamiento frente al mismo (3).

\section{CASO APORTADO}

Varón de 49 años, peruano con 10 años de residencia en España y último viaje a su país en 1995, sin ningún antecedente de interés salvo agresión sexual en 1996, con severo desgarro del canal anal que produjo rectorragia que precisó de transfusión de dos concentrados de hematíes; no hábitos tóxicos ni prácticas de riesgo para infección por VIH. Consulta por cuadro de 4-5 deposiciones al día, líquidas, sin productos patológicos, de unos 6 meses de evolución, añadiéndose fiebre de hasta $39^{\circ} \mathrm{C}$ en los dos últimos meses. Pérdida de 2-3 Kg de peso en este tiempo; discreto dolor abdominal; cefalea holocraneal. Resto de anamnesis por aparatos sin datos reseñables.

En la exploración física, fiebre de $38,5^{\circ} \mathrm{C}$ bien tolerada, con auscultación cardio-pulmonar normal, abdomen discreta y difusamente doloroso a la palpación, sin signos de irritación peritoneal, tacto rectal con esfínter conservado y sin alteraciones, y exploración neurológica rigurosamente normal.

Datos de laboratorio: Velocidad de Sedimentación Globular (VSG) 35; hemograma, bioquímica sanguínea, estudio básico de coagulación, hormonas tiroideas y rutinario de orina normales. Anti Hbc y anti HBe positivos; VHC, RPR, Rosa de Bengala, Ac. Leishmania, Ag. criptococo y Mantoux, negativos. Antigenemia para CMV 70 células; Ac. Toxoplasma positivo.VIH positivo (ELISA y

Trabajo aceptado: 23 de Febrero de 1999 
Western Blot). CD4 96; Carga Viral 153.690 copias. Hemocultivos (X3) negativos (2 tandas); parásitos en fresco negativo para cryptosporidium y microsporidia; enteropatógenos y toxina de Clostridium difficile negativos; jugo duodenal y biopsia de $2^{\mathrm{a}}$ porción duodenal sin patógenos; se aisla CMV en cultivo de biopsia de colon, siendo el resto del estudio a dicho nivel negativo; se aísla CMV en cultivo celular de orina.

Fondo de ojo sin datos de retinitis por CMV. Pruebas de imagen: Rx tórax, ecografía abdominal, esofago-gastroscopia, colonoscopia y tránsito gastrointestinal sin alteraciones reseñables. En la TAC craneal, se objetiva una masa intra-axial, que presenta realce de predominio anular tras el contraste IV, centrada en la región del brazo anterior de la cápsula interna y ganglios basales izquierdos, con importante edema vasogénico asociado (diagnóstico diferencial toxoplasmosis/linfoma).

Se inició tratamiento con Ganciclovir IV para tratamiento de la infección por CMV, así como Sulfadiacina y Pirimetamina VO, más corticoide IV para la masa cerebral, con desaparición de la fiebre y normalización de la diarrea a las 48 horas de iniciado el tratamiento. A los 14 días de iniciado el tratamiento el paciente seguía asintomático; se repitió la TAC craneal, objetivándose disminución considerable del tamaño de la lesión, lo que apoya el diagnóstico de toxoplasmosis cerebral.

\section{DISCUSIÓN}

Diversos estudios demuestran la alta frecuencia de infección por CMV en los pacientes infectados por VIH (entre el 70 y el $100 \%$ ), sobre todo en estadios con inmunosupresión severa (50-100 CD4); se piensa que es debida a la reactivación de una infección latente (1).

Generalmente se requieren estudios histológicos que demuestren las inclusiones citomegálicas en "ojo de buho" para su diagnóstico, pero la exclusión de otros agentes etiológicos que puedan ocasionar el proceso estudiado y la demostración de infección por CMV mediante cultivo, PCR, antigenemia elevada justifican el tratamiento para CMV (3).

La afectación digestiva es la segunda en frecuencia después de la retinitis, pudiéndose afectar cualquier porción del tracto digestivo, desde esófago hasta el recto (2). La colitis es la forma más frecuente de afectación del tubo digestivo, siendo la clínica de dolor abdominal y diarrea (en ocasiones con sangre), junto con fiebre, disminución de peso y anorexia. El abdomen agudo por perforación (la complicación más peligrosa) es infrecuente (4). La colitis por CMV se da en un 5$10 \%$ de los pacientes con SIDA; la diarrea se da en el $60 \%$ de los pacientes con SIDA, siendo el CMV el agente causal como media en el $20 \%$ de los casos (segunda causa de diarrea en el paciente con SIDA) (5). Generalmente se presenta en pacientes con SIDA ya establecido, pero puede ser el índice diagnóstico de SIDA en un $25 \%$ de casos (6).

En la colonoscopia se suelen ver hemorragias submucosas y/o úlceras (similar a las lesiones de la colitis ulcerosa) (7), aunque en ocasiones puede ser normal (1)

En la actualidad disponemos de tres fármacos con actividad frente a CMV: Ganciclovir, Foscarnet y Cidofovir. Pese a la eficacia que los tres han demostrado frente al CMV, ninguno ha resuelto todavía el problema de los efectos adversos, la "dificultad" para su administración (intravenosa) y la posibilidad de recidiva de la enfermedad tras su suspensión.

En el caso de la colitis parece que se precisa de tratamientos de inducción más prolongados, y en ocasiones terapia de mantenimiento, siendo lo más habitual dos semanas, y en caso de persistencia de los síntomas, hasta cuatro semanas (8).

Para terminar, nos gustaría comentar tres aspectos del caso que nos parecen importantes.Primero, la importancia de la epidemiología: después de la agresión sexual no se solicitó la serología para VIH, con lo que el diagnóstico se ha retrasado; segundo, resaltar la utilidad de los protocolos consensuados para el estudio de fiebre en el paciente VIH positivo, con el objetivo de no olvidarse de ninguna posibilidad, dada la amplitud de diagnósticos posibles (9); y tercero, la precaución ante la realización de punción lumbar en pacientes VIH positivos aun sin focalidad neurológica y fondo de ojo normal, dada la posible existencia de masa con edema y el riesgo de enclavamiento que dicha punción podría ocasionar.

\section{Bibliografía}

1. Drew WL, Jacobson MA. Cytomegalovirus. En: Cohen PT, Sande M.A., Volberding P.A. The AIDS Knowledge Base. 2nd. ed Boston: Little, Brown and Company; 1994; 6,13: 1-12.

2. Cello J.P. Gastrointestinal Tract Manifestations of AIDS. En: Sande MA, Volberding PA. The Medical Management of AIDS. 5th ed. Philadelphia: WB. Saunders Company. 1997; 181-113.

3. Verdejo J. Enfermedad por Citomegalovirus. En: Soriano V, GonzálezLahoz J. Manual del SIDA. $2^{a}$ ed Madrid: IDEPSA. 1997; 328-338.

4. Fernández Sola A, Valle Callol JA, Capdevilla Morell JA, Ribera Pascuet E, Raventos Estelle A, Martínez Vázquez JM. Abdomen agudo secundario a infección por citomegalovirus. An Med Interna (Madrid) 1992; 9: 33-35.

5. González Anglada Ma I, Barbado FJ, Arribas JR, Pérez G, Casal V, Vázque JJ, García Viera M. Ileitis terminal por criptosporidium y cito-

megalovirus en un paciente con SIDA. An Med Interna (Madrid) 1994; 11: 139-141.

6. Dieterich DT, Rahmin M. Cytomegalovirus colitis in AIDS: Presentation in 44 patients and a rewiew of the literature. J AIDS 1991; 4 Supl 1: 529535 .

7. Soriano V, González-Lahoz J. Síndromes clínicos en la infección por el VIH (Segunda de dos partes). An Med Interna (Madrid) 1992; 9: 501508 .

8. Blanshard C, Benhamou Y, Dohin E et al. Treatment of AIDS-associated Gastrointestinal Cytomegalovirus Infection with Foscarnet and Ganciclovir: A Randomized Comparison. Clin Infect Dis 1995; 172; 622-628.

9. Lozano de León F, León Jiménez EM, Gómez-Mateos JM, Corzo Delgado JE. Fiebre de origen desconocido: actitudes diagnósticas. Medicine $1998 ; 7 ; 3558-3566$. 